\title{
PREDICTION AND COMPARISON OF DOWNLINK ELECTRIC-FIELD AND UPLINK LOCALIZED SAR VALUES FOR REALISTIC INDOOR WIRELESS PLANNING
}

\author{
David Plets ${ }^{a *}$,Wout Joseph ${ }^{\text {a }}$, Sam Aerts ${ }^{\text {a }}$, Kris Vanhecke ${ }^{\text {a }}$, Günter Vermeeren ${ }^{\text {a }}$, Luc Martens ${ }^{\text {a }}$ \\ ${ }^{a}$ Wireless\&Cable - iMinds/Ghent University, Dept. of Information Technology \\ G. Crommenlaan 8 box 201, B-9050 Ghent, Belgium
}

Received on Month Day, Year, revised on Month Day, Year, accepted on Month Day, Year

\begin{abstract}
In this paper, for the first time a heuristic network calculator for both whole-body exposure due to indoor base station antennas or access points (downlink exposure) and localized exposure due to the mobile device (uplink exposure) in indoor wireless networks is presented. As an application, three phone call scenarios are investigated (Universal Mobile Telecommunications System (UMTS) macrocell, UMTS femtocell, WiFi voice-over-IP) and compared with respect to the electric-field strength and localized Specific Absorption Rate (SAR) distribution. Prediction models are created and successfully validated with an accuracy of $3 \mathrm{~dB}$. The benefits of the UMTS power control mechanisms are demonstrated. However, dependent on the macrocell connection quality and on the user's average phone call connection time, also the macrocell solution might be preferential from an exposure point of view for the considered scenario.
\end{abstract}

\section{INTRODUCTION}

The vast expansion of the use of wireless networks in everyday life has led to a greater awareness of exposure of the general public to RF (radiofrequency) electromagnetic fields used for wireless telecommunication. International organizations such as IEEE [1] and ICNIRP (International Commission on Non-Ionizing Radiation Protection) [2] have issued safety guidelines to limit the maximal electric-field strength due to wireless communications. Also on a national level, authorities have implemented laws and norms to limit the exposure to electromagnetic fields. A lot of research has been done on the characterization of RF exposure (e.g., [3-7]), and measurements have indicated that exposure in indoor environments cannot be neglected [8]. Most exposure studies merely focus on fields generated due to traffic from base station to user device (downlink), but in reality also the localized Specific Absorption Rate (SAR) due to the electromagnetic waves induced (e.g., in the user's head) by the user device should be considered (uplink). Software tools for predicting the received signal quality $[9-13,17,18]$ very often do not account for exposure values. Moreover, localized exposure was never considered up to now in network planners. In [19], the authors presented the WiCa Heuristic Indoor Propagation Prediction (WHIPP) tool, a set of heuristic planning algorithms, experimentally validated for network planning in indoor environments [19]. The path loss prediction algorithm takes into account the effect of the environment on the wireless propagation channel and bases its calculations on the determination of the dominant path between transmitter and receiver, i.e., the path along which the signal encounters the

*Corresponding author: david.plets@intec.ugent.be lowest obstruction. The WHIPP tool is designed for optimal network planning with a minimal number of access points (AP) [19]. In [20], this tool was extended for automatic network planning with a limited or even minimized downlink exposure in indoor wireless networks, without impairing coverage.

In this paper, prediction algorithms are created to simulate and visualize electric-field strengths due to downlink traffic and localized SAR values due to uplink traffic. Downlink exposure will be expressed in terms of whole-body exposure due to the electricfields $\mathrm{E}$ originating from the base stations or APs, while uplink exposure will be expressed in terms of localized $\mathrm{SAR}_{10 \mathrm{~g}}$ (SAR in $10 \mathrm{~g}$ tissue [8]) values due to the mobile device's transmitted signal. To the authors' knowledge, no network planning tools are yet available that also simulate localized SAR. We will define three phone call scenarios and compare the human exposure due to downlink traffic (electric fields) and due to uplink traffic $\left(\mathrm{SAR}_{10 \mathrm{~g}}\right)$ : a user device connecting to a(n outdoor) Universal Mobile Telecommunications System (UMTS) macrocell, to an indoor UMTS femtocell network, and to an indoor WiFi AP network.

\section{CONNECTION SCENARIOS}

Three connection scenarios will be investigated: connection with an outdoor UMTS macrocell, an indoor UMTS femtocell, and an indoor WiFi AP. For all scenarios, we will investigate the electric-field and SAR distributions inside the office building depicted in Fig. 1. The building is $90 \mathrm{~m}$ long and $17 \mathrm{~m}$ wide and consists of concrete walls (grey) and layered drywalls (brown).

Despite their lower radiated power, indoor base stations (WiFi APs and UMTS femtocell base stations 


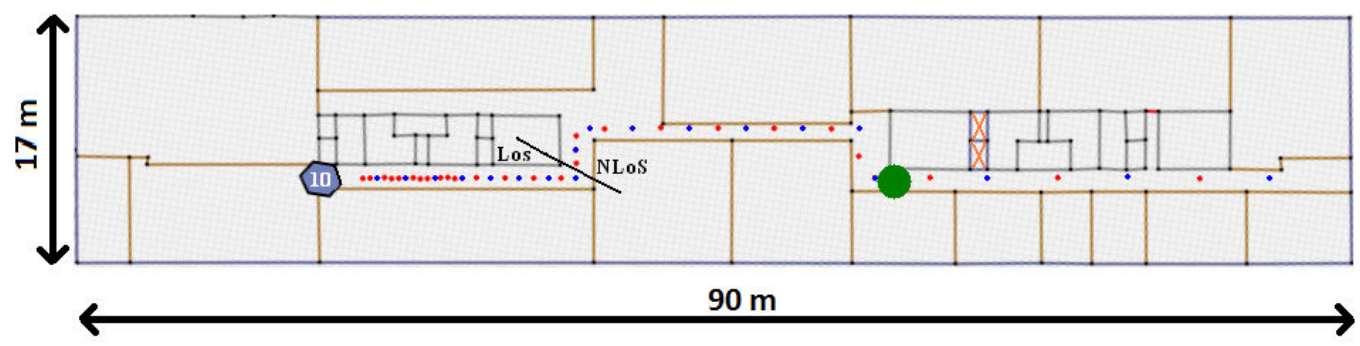

Figure 1. Ground plan of office building with indication of measurement locations for the validation of the prediction model for the MP's transmit and receive power (Hexagon = femtocell base station location for UMTS model validation measurements; red $\mathrm{dot}=\mathrm{UMTS}$ femtocell measurement location; blue dot = UMTS macrocell measurement location; grey walls = concrete; brown walls = layered drywall; green dot = predicted optimal location for UMTS femtocell base station/WiFi access point).

(FBS)) are generally expected to cause higher electricfield strengths (downlink) inside a building than macrocell base stations (MBS), due to the proximity of the user to the base station. On the other hand, localized SAR values (uplink) are expected to be lower when connecting to indoor base stations, again due to the proximity of the indoor base station. This paper aims to quantify and compare the distribution of the exposure values during a phone call.

\subsection{Connection with WiFi access points}

For the WiFi AP scenario, the WHIPP planning tool will first design a network according to the WiFi coverage requirements in the different rooms, the WiFi (voice call) receiver sensitivities and transmit powers of both the AP and the considered mobile phone (type Nokia N95), and the network planner's path loss models. The WHIPP tool places WiFi APs to meet a certain coverage requirement in the different rooms of the building [19]. When optimizing the different networks for a certain coverage, a user-defined requirement always has to be met for each room, using a $90 \%$ shadowing margin and $95 \%$ fading margin. Shadowing and fading margins are assumed at $7 \mathrm{~dB}$ and $5 \mathrm{~dB}$ respectively. The orange ' $\mathrm{X}$ '-marks in Fig. 1 indicate the elevator shaft, which is designed in metal and is assumed not to require coverage. At all other locations, a minimal throughput of only $1 \mathrm{Mbps}$ (lowest possible WiFi throughput) is required (both for uplink and downlink), an assumption justified by the low bit rates required for WiFi phone calls [24]. At this bit rate, WiFi uses Direct-Sequence Spread Spectrum (DSSS) as modulation technique, just like UMTS

\subsection{Connection with UMTS femtocell}

For the UMTS femtocell scenario, the coverage requirement of the Adaptive Multe-Rate Speech Codec (AMR) is assumed, i.e., $12.2 \mathrm{kbps}$. The WHIPP planning tool will again design a network by placing a number of UMTS femtocell base stations on the ground plan, based on the same shadowing and fading margins as for the WiFi AP scenario, but also on the specific UMTS (voice call) receiver sensitivities and path loss models. The locations where coverage is required, are the same as for the WiFi scenario (see Fig. 1). After constructing the prediction model for the device transmit powers (based on the receive sensitivity of the UMTS FBS), the WHIPP tool will be used for the prediction of the electric-field and localized SAR values.

\subsection{Connection with UMTS macrocell}

In this scenario, the mobile phone connects to an outdoor UMTS macrocell. The investigated building of Fig. 1 has macrocell UMTS coverage over the entire building. Since the WHIPP tool is specifically developed for indoor environments, it will not be used for the exposure calculations. Moreover, in order to perform adequate link budget simulations, the tool would require accurate knowledge about the MBS transmit power and the path loss between the MBS and the mobile phone device inside the building, depending on the outdoor environment and the building penetration loss. Therefore, electric-field and SAR values will be determined from measurements inside the building. Based upon these measurements and on the UMTS power control principle, a simulation of other locations of the MBS (relative to the considered office building) will be investigated.

\section{WIRELESS EQUIPMENT}

In this section the wireless equipment and its characteristics are described. A separation will be made between the characteristics relevant for downlink traffic and those relevant for uplink traffic. As mentioned before, the receive and transmit characteristics presented in this section will not be used for the UMTS macrocell scenario. For that scenario, we will perform reallife measurements to obtain representative electric-field 
and SAR values, instead of relying on link budget calculations.

\subsection{Downlink: From Base Station to Mobile Phone Device}

In this section, downlink characteristics of the base stations (UMTS FBS, WiFi AP) and the mobile device that will be used in the three simulation scenarios are discussed.

\subsubsection{Base station transmit characteristics}

This section discusses the characteristics of the different wireless base stations (UMTS FBS, WiFi AP).

- UMTS femtocell: For the SAR and electric-field simulations and measurements for a UMTS FBS, a Huawei (Shenzhen, Guangdong, China) base station (type ePico3801B) was used. It has an Equivalent Isotropically Radiated Power (EIRP) of $10 \mathrm{dBm}$ and operates at a frequency of $2151.6 \mathrm{MHz}$ for downlink traffic. The validation measurements are performed during a $3 \mathrm{G}$ phone call. Table 1 shows the EIRP of the UMTS FBS.

WiFi access point: For the WiFi AP simulation, a DLink DI-624 AirPlusXtremeG WiFi AP is considered. WHIPP simulations have already been validated with measurements for this AP in [20]. This type of AP will also be used for the simulations in the WiFi connection scenario, with the EIRP set at $10 \mathrm{dBm}$ (see Table 1, 'AP').

\begin{tabular}{|r|r|r|r|r|}
\hline & $\begin{array}{r}\mathbf{T P}_{\text {req }}^{\text {rec }} \\
\text { rensitivity } \\
{[\mathbf{d B m}]}\end{array}$ & $\begin{array}{r}\text { receiver } \\
\text { [ransmit } \\
\text { EIRP }\end{array}$ & $\begin{array}{r}\mathbf{S A R}_{\mathbf{1 0 g}}^{\max } \\
{[\mathbf{d B / k g}]}\end{array}$ \\
\hline \hline MP UMTS & $12.2 \mathrm{kbps}$ & -95.1 & variable & 0.415 \\
MP WiFi & $1 \mathrm{Mbps}$ & -98.4 & 20 & 0.049 \\
\hline \hline UMTS FBS & $12.2 \mathrm{kbps}$ & -110 & 10 & - \\
WiFi AP & $1 \mathrm{Mbps}$ & -98.4 & 10 & - \\
\hline
\end{tabular}

Table 1. Required received throughput $\mathrm{TP}_{\mathrm{rec}}^{\mathrm{rec}}$, receiver sensitivities and EIRP of UMTS and WiFi chipsets of mobile phone MP, UMTS femtocell base station (FBS), and WiFi access point (AP), and $S A R_{10 \mathrm{~g}}^{\max }$ values for UMTS and WiFi chipsets of MP.

\subsubsection{Mobile phone receive sensitivities}

For all tests and simulations, a Nokia N95 (Espoo, Finland) mobile phone was used. The device was equipped with a Field Test Display (FTD) program, a software application allowing monitoring technical details, such as the power $\mathrm{P}_{\mathrm{Tx}}[\mathrm{dBm}]$ emitted by the device and the Received Signal Strength Indication (RSSI) $[\mathrm{dBm}]$. The measured RSSI values will be converted into values of the actual power received by the device (see Section 5).

The assumed UMTS receiver sensitivity $\mathrm{P}_{\mathrm{MP} \text {, sen }}^{\mathrm{UMTS}}$ is $-95.1 \mathrm{dBm}$ (see 'MP UMTS', Table 1). This value is based on an SNR (Signal-to-Noise Ratio) of $7 \mathrm{~dB}$ for the AMR bit rate of $12.2 \mathrm{kbps}$, an UMTS processing gain $\mathrm{G}_{\text {proc }}$ of $10 \mathrm{~dB}$, an implementation loss IL of $2 \mathrm{~dB}$, a noise figure $\mathrm{NF}$ of $8 \mathrm{~dB}$, an interference margin IF of $6 \mathrm{~dB}$, and a thermal noise floor $\mathrm{P}_{\text {noise }}$ of $-108.1 \mathrm{dBm}$ (bandwidth $=5 \mathrm{MHz}$ ). It is calculated according to the following formula.

$$
\mathrm{P}_{\mathrm{MP}, \mathrm{sens}}^{\mathrm{UMTS}}=\mathrm{P}_{\text {noise }}+\mathrm{SNR}-\mathrm{G}_{\text {proc }}+\mathrm{IL}+\mathrm{NF}+\mathrm{IF},
$$

The assumed WiFi receiver sensitivity is $-98.4 \mathrm{dBm}$ (see 'MP WiFi', Table 1), based on the specifications of [25] for a required throughput of 1 Mbps for a typical $802.11 \mathrm{~b} / \mathrm{g}$ receiver chipset.

\subsection{Uplink: From Mobile Phone Device to Base Station}

In this section, the uplink characteristics (transmit power and $\mathrm{SAR}_{10 \mathrm{~g}}^{\max }$ values) of the mobile device and the base stations (receive sensitivities) will be discussed.

\subsubsection{Mobile Phone Transmit Characteristics}

The uplink localized SAR values will depend on the transmit power of the device and on the $\mathrm{SAR}^{\max }$ values inherent to the device. For the determination of maximum spatial peak SAR values in a $10 \mathrm{~g}$ cube $\left(\mathrm{SAR}_{10 \mathrm{~g}}^{\max }[\mathrm{W} / \mathrm{kg}]\right)$, Federal Communications Commission (FCC) values for the Nokia mobile device in the $1800 \mathrm{MHz}$ (UMTS) and the $2400 \mathrm{MHz}$ (WiFi) frequency band were used, based on certified compliance measurements [26,27] (10g and $1 \mathrm{~g}$ values are provided). This means that our SAR calculations will be worst-case and possibly an overestimation of the real localized SAR. Furthermore, the localized SAR values will depend on the exact position of the device relative to the body, and to a lesser extent on the morphology (child, adult). The differences in peaklocalized SAR due to the age-dependent changes of the tissue dielectrics are less than $1.5 \mathrm{~dB}[34,35]$. The differences in peak-localized SAR among head models can reach an order of magnitude of $3 \mathrm{~dB}$ [35].

UMTS: For the $1800 \mathrm{MHz}$ band, no UMTS SAR values were reported in [26]. Therefore we use the FCC document of the US version of the same mobile phone (WCDMA1900), assuming the $\mathrm{SAR}_{10 \mathrm{~g}}$ values will be the same. Hence, from [27], we obtain a $\mathrm{SAR}_{10 \mathrm{~g}}^{\max }$ value of $0.476 \mathrm{~W} / \mathrm{kg}$ for an 
antenna EIRP of $23.6 \mathrm{dBm}$, which rescales to a $\mathrm{SAR}_{10 \mathrm{~g}}^{\max }$ value of $0.415 \mathrm{~W} / \mathrm{kg}$ for an antenna EIRP of $0.2 \mathrm{~W}$ or $23 \mathrm{dBm}$ (see Table 1). This maximal value is obtained for a tilted position of the phone on the left side of the phantom head [27].

The $\mathrm{SAR}_{10 \mathrm{~g}}^{\max }$ value will also be used to calculate localized SAR values for the macrocell scenario, since this value is essential to convert device transmit power values to $S A R$ values.

WiFi: For the $2400 \mathrm{MHz}$ band, an $\mathrm{SAR}_{10 \mathrm{~g}}^{\max }$ value of $0.064 \mathrm{~W} / \mathrm{kg}$ was reported in [26] for an antenna EIRP of $21.2 \mathrm{dBm}$ [26], which rescales to a $\mathrm{SAR}_{10 \mathrm{~g}}^{\max }$ value of $0.049 \mathrm{~W} / \mathrm{kg}$ for an antenna EIRP of $0.1 \mathrm{~W}$ or $20 \mathrm{dBm}$ and a duty cycle of $100 \%$ (see Table 1). This maximal value is obtained for a position of the phone next to the right cheek of the phantom head [26].

\subsubsection{Base station receive sensitivities}

The uplink communication will also be dependent on the receive sensitivities of the UMTS base station or the WiFi AP.

WiFi access point: The same WiFi chipset and hence also the same sensitivity is assumed as for the $\mathrm{WiFi}$ receiver inside the mobile phone, i.e., $-98.4 \mathrm{dBm}$.

- UMTS femtocell: The receive sensitivity is assumed at $-110 \mathrm{dBm}$, in the validation phase of the prediction models later in this paper. The uplink frequency from mobile phone to FBS is 1957.6 MHz.

The considered base station receive sensitivities are listed in Table 1.

\section{SIMULATION METHOD: ELECTRIC-FIELD AND SAR MODELS}

The exposure values for the different connection scenarios will be separately calculated for uplink traffic and downlink traffic. Downlink exposure will be expressed as a function of the electric-field strength generated by the incident waves from the base station (macrocell, femtocell, or AP). Most measurement campaigns verify compliance with ICNIRP electricfield reference levels, e.g., [3-8]. Also, national and international authorities (e.g., Belgium, Switzerland,...) base their regulations on electric-field levels. Uplink exposure will be expressed by a localized $\mathrm{SAR}_{10 \mathrm{~g}}$ value in the head due to transmission from user device to the base station, a measure also used in [28-32].

\subsection{Downlink: Electric-field model \\ 4.1.1 UMTS femtocell and WiFi access point}

For the predicted electric-field strength $\mathrm{E}_{\mathrm{MP}}^{\mathrm{pred}}[\mathrm{V} / \mathrm{m}]$ at the location of the mobile phone MP, the following equation was derived and validated in [20]:

$$
\mathrm{E}_{\mathrm{MP}}^{\mathrm{pred}}=10 \frac{\mathrm{EIRP}-43.15+20 \cdot \log _{10}(\mathrm{f})-\mathrm{PL}}{20},
$$

with a given EIRP $[\mathrm{dBm}]$ of the base station, operating at frequency $\mathrm{f}[\mathrm{MHz}]$. For the calculation of the path loss PL $[\mathrm{dB}]$ between base station and mobile phone, the extensively validated WHIPP model of [19] is used. For WiFi APs, $\mathrm{E}_{\mathrm{MP}}^{\mathrm{pred}}$ is multiplied by the square root of the duty cycle (here assumed $2 \%$, based on measured 'Skype voice' duty cycles in [16]).

\subsubsection{UMTS macrocell}

For the prediction of the electric-field strength $\mathrm{E}_{\mathrm{MP}, \text { macrocellBS }}^{\mathrm{pred}}$ due to the UMTS macrocell, we have based ourselves on actual received power measurements, instead of using an expression similar to eq. (2). These values will be presented in Section 6.

\subsection{Uplink: Localized SAR model}

For the calculation of the localized $\mathrm{SAR}_{10 \mathrm{~g}}[\mathrm{~W} / \mathrm{kg}]$, the following equation is used [21,33].

$$
\mathrm{SAR}_{10 \mathrm{~g}}=\frac{\mathrm{P}_{\mathrm{Tx}}}{\mathrm{P}_{\mathrm{Tx}}^{\max }} \cdot \mathrm{SAR}_{10 \mathrm{~g}}^{\max }
$$

where $\mathrm{P}_{\mathrm{Tx}}[\mathrm{W}]$ is the power emitted by the user device, $\mathrm{P}_{\mathrm{Tx}}^{\max }[\mathrm{W}]$ is the maximal power emitted by the user device, and $\mathrm{SAR}_{10 \mathrm{~g}}^{\max }[\mathrm{W} / \mathrm{kg}]$ is the maximum spatial peak SAR in a $10 \mathrm{~g}$ cube, a value measured in a standard configuration [27].

For the considered device, a Nokia N95, SAR $\max _{10 \mathrm{~g}}$ for a radiated power $\mathrm{P}_{\mathrm{Tx}}^{\max }$ of $23 \mathrm{dBm}$ is $0.415 \mathrm{~W} / \mathrm{kg}$ (see Table 1). The value $\mathrm{P}_{\mathrm{Tx}}^{\max }$ of $23 \mathrm{dBm}$ for UMTS is also stated in [21] and is confirmed by measurements with the device. For $\mathrm{WiFi}, \mathrm{SAR}_{10 \mathrm{~g}}$ for a UMTS radiated power $\mathrm{P}_{\mathrm{Tx}}^{\max }$ of $20 \mathrm{dBm}$ is $0.049 \mathrm{~W} / \mathrm{kg}$ (see Table 1 ). In order to predict the localized SAR values, an accurate prediction of the emitted power $\mathrm{P}_{\mathrm{Tx}}$ is required (see equation (3)).

For uplink WiFi traffic, $\mathrm{P}_{\mathrm{Tx}}$ in eq. (3), will be denoted as $\mathrm{P}_{\mathrm{Tx}, \text { wifi }}^{\text {pred }}[\mathrm{W}]$, the mobile phone's emitted power as calculated by the WHIPP tool.

$$
\mathrm{P}_{\mathrm{Tx}, \text { wifi }}^{\text {pred }}=\mathrm{P}_{\max } \times \frac{\mathrm{DC}}{100},
$$

with DC [\%] the duty cycle, again assumed at $2 \%$ [16]. $\mathrm{P}_{\max }[\mathrm{W}]$ is the maximal emitted power, which is typically fixed for WiFi. We will assume $\mathrm{P}_{\max }$ to be $20 \mathrm{dBm}$ or $0.1 \mathrm{~W}$, irrespective of the 
connection quality. No power control will be used in the uplink WiFi scenario.

For uplink UMTS to femtocell, $\mathrm{P}_{\mathrm{Tx}}$ from equation (3), will be predicted by $\mathrm{P}_{\mathrm{Tx} \text { femto }}^{\text {pred }}$ the mobile phone's emitted power as predicted by the WHIPP tool. In UMTS operation, power control is used; $\mathrm{P}_{\mathrm{Tx}, \text { femto }}^{\text {pred }}$ varies between $-57 \mathrm{dBm}$ and $23 \mathrm{dBm}$ [21], depending on the connection quality and the base station sensitivity. The mobile device's emitted power $\mathrm{P}_{\mathrm{Tx}, \text { femto }}^{\text {pred }}$ towards the FBS is modeled as follows:

$$
\mathrm{P}_{\mathrm{Tx}, \text { femto }}^{\text {pred }}=\mathrm{P}_{\text {sens }}+\mathrm{PL}
$$

where $P_{\text {sens }}[\mathrm{dBm}]$ is the sensitivity of the UMTS FBS for maintaining a UMTS phone call. PL $[\mathrm{dB}]$ is the path loss between base station and user device, which will be predicted by the WHIPP tool [19]. The lower limit for $\mathrm{P}_{\mathrm{Tx}}$ values will be $-57 \mathrm{dBm}$, the lowest observed emitted power for the user device (see also [21]). The model for $\mathrm{P}_{\mathrm{Tx}}$ will be validated in the following sections.

For uplink UMTS to macrocell, we will again start from actual downlink power values from and uplink power values to the existing MBS, measured in the considered building of Fig. 1. Based on these values, other MBS locations will be simulated by varying the received power in steps of $10 \mathrm{~dB}$. Due to the power control mechanism, these downlink simulations will allow to also determine the corresponding uplink power $\mathrm{P}_{\mathrm{Tx}, \text { macro. }}^{\text {pred }} \mathrm{SAR}_{10 \mathrm{~g}}$ values will then be calculated according to equation (3)).

\section{VALIDATION OF PREDICTION MODEL FOR MOBILE PHONE UMTS TRANSMIT AND RECEIVE POWER}

For uplink UMTS traffic, power control mechanisms will be applied at the user device, where the device transmit power is adapted according to eq. (5). However, since $P_{\text {sens }}$ is unknown in eq. (5), its value will be determined using calibration. Further, since the relation between the Nokia's RSSI values and the actual received power is unknown (downlink traffic), we will investigate whether the received power $\mathrm{P}_{\text {rec,femto }}^{\text {meas }}$ can be modeled as a shifted version of the measured RSSI (RSSI $I_{\text {rec,femto }}^{\text {meas }}$ ):

$$
\mathrm{P}_{\text {rec,femto }}^{\text {meas }}[\mathrm{dBm}]=\mathrm{RSSI}_{\text {rec,femto }}^{\text {meas }}[\mathrm{dBm}]+\mathrm{F} \text {, }
$$

with $\mathrm{F}$ a constant scaling factor. Hereby, based on previous validations of the WHIPP tool [19], it is assumed that the WHIPP tool is an accurate predictor

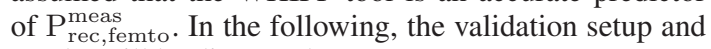
results will be discussed.

\subsection{Validation measurement setup}

The set of validation measurements is performed in the office building depicted in Fig. 1, in which a UMTS FBS is installed, at a height of $2 \mathrm{~m}$. The location of the FBS is marked with a purple hexagon on Fig. 1; its EIRP of $10 \mathrm{dBm}$ is indicated inside the hexagon. At 45 locations inside the office building, the RSSI and the transmitted uplink power $\left(\mathrm{P}_{\mathrm{Tx}}\right)$ levels were monitored with the Nokia mobile phone device (see Section 3.2.2). The 23 locations in the corridor with the FBS are line-of-sight (LoS), the other 22 are Non Line-of-Sight (NLoS). The measurements were performed during a UMTS phone call.

During each of the 45 measurements, the mobile phone was held horizontally at a height of $1.3 \mathrm{~m}$ above the floor to allow reading the communication parameter values). The RSSI, the maximum $\left(\mathrm{P}_{\mathrm{Tx}}^{\max }\right)$ and the minimum $\left(\mathrm{P}_{\mathrm{Tx}}^{\min }\right)$ uplink power levels were recorded for four different orientations (90 degrees apart). In order to reduce the influence of the user's position and the mobile antenna directivity [7], the four RSSI values, $\mathrm{P}_{\mathrm{Tx}}^{\max }$, and $\mathrm{P}_{\mathrm{Tx}}^{\min }$ values were averaged, yielding one (averaged) RSSI, one (averaged) $\mathrm{P}_{\mathrm{Tx}}^{\max }$, and one (averaged) $\mathrm{P}_{\mathrm{Tx}}^{\min }$ value per location. $\mathrm{P}_{\mathrm{Tx}}^{\mathrm{avg}}$ is defined as the average of $\mathrm{P}_{\mathrm{Tx}}^{\max }$ and $\mathrm{P}_{\mathrm{Tx}}^{\min }$. More measurements with a smaller separation were performed close to the FBS (see Fig. 1), because of the more rapid variation of the device uplink and downlink power there.

\subsection{Validation results}

Fig. 2 shows the measured $\left(\mathrm{P}_{\mathrm{Tx}, \text { femto }}^{\text {meas }}\right)$ and predicted $\left(\mathrm{P}_{\mathrm{Tx}}^{\text {pred }}\right.$ femto $)$ device uplink power transmitted to the UMTS FBS (see equation (5)) at the different measurement locations, with an indication of the LoS and NLoS points. The best predictions for the uplink power $\mathrm{P}_{\mathrm{Tx}}^{\text {pred,femto }}$ are obtained by calibrating the value of $\mathrm{P}_{\text {sens }}$ at $-110 \mathrm{dBm}$. The predicted uplink power is situated between the maximum and minimum measured uplink powers and agrees excellently with its average uplink power $\mathrm{P}_{\mathrm{Tx}}^{\text {avg, meas }}$.

Table 2 lists the differences between the predicted uplink power $\mathrm{P}_{\mathrm{Tx}}^{\text {pred femto }}$ and the measured average uplink power $\mathrm{P}_{\mathrm{Tx}}^{\mathrm{avg} \text {, memto }}$, as well as the corresponding standard deviation $\sigma_{\delta}$ of the differences. Fig. 2 and Table 2 show that very low deviations are obtained $(<$ $3 \mathrm{~dB}$ ). The very low absolute differences and standard deviations indicate the ability of the WHIPP tool to perform accurate predictions for $\mathrm{P}_{\mathrm{Tx}}^{\mathrm{pred}}$,femto (eq. (5)), the power emitted by the user device in case of power control. Substitution of eq. (5) into eq. (3) thus allows an accurate (worst-case) prediction of localized SAR values in the building for the UMTS case.

Fig. 3 shows the measured average $\left(\mathrm{P}_{\text {rec,femto }}^{\text {avg, meas }}\right)$ and predicted $\left(\mathrm{P}_{\text {rec,femto }}^{\text {pred }}\right)$ received power values from the UMTS FBS at the different measurement locations, 


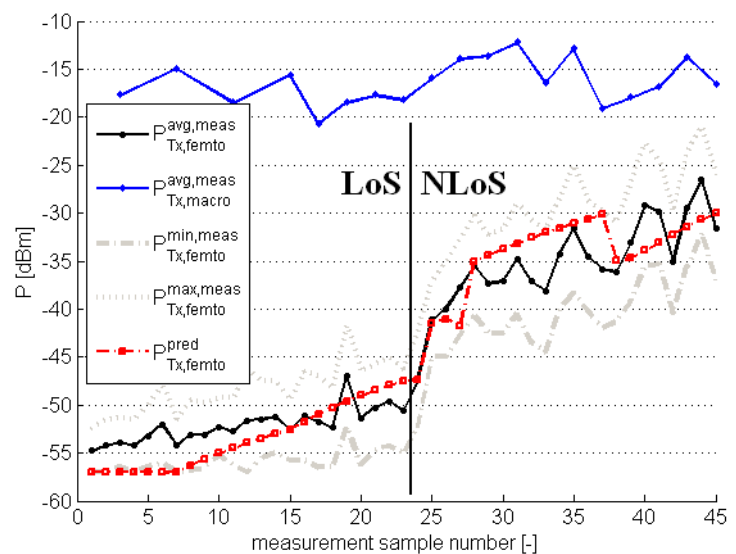

Figure 2. Measured device uplink power to macrocell base station $\left(\mathrm{P}_{\text {Tx,macro }}^{\text {avg,meas }}\right)$ and measured $\left(\mathrm{P}_{\text {Tx,femto }}^{\text {avg,meas }}\right)$ and predicted $\left(\mathrm{P}_{\mathrm{Tx} \text {,femto }}^{\text {pred }}\right)$ device uplink power transmitted to FBS as a function of measurement sample number (increasing measurement number corresponds with increasing distance to FBS (see Fig. 1)).

\begin{tabular}{|r|rrrr|}
\hline $\mathrm{P}_{\text {Tx }, \text { femto }}$ & $\begin{array}{r}\delta_{\text {avg }} \\
{[\mathrm{dB}]}\end{array}$ & $\begin{array}{r}\sigma_{\delta} \\
{[\mathrm{dB}]}\end{array}$ & $\begin{array}{r}|\delta|_{\text {avg }} \\
{[\mathrm{dB}]}\end{array}$ & $\begin{array}{r}\sigma_{|\delta|} \\
{[\mathrm{dB}]}\end{array}$ \\
\hline \hline LoS & 1.30 & 2.25 & 2.34 & 1.05 \\
\hline NLoS & -0.75 & 3.16 & 2.66 & 1.77 \\
\hline All & 0.30 & 2.89 & 2.50 & 1.44 \\
\hline \hline P $_{\text {rec,femto }}$ & $\delta_{\text {avg }}$ & $\sigma_{\delta}$ & $|\delta|_{\text {avg }}$ & $\begin{array}{r}\sigma_{|\delta|} \\
{[\mathrm{dB}]} \\
{[\mathrm{dB}]}\end{array}$ \\
{$[\mathrm{dB}]$} & {$[\mathrm{dB}]$} \\
\hline LoS & -1.31 & 3.54 & 3.19 & 1.92 \\
\hline NLoS & 1.25 & 2.26 & 2.13 & 1.40 \\
\hline All & -0.06 & 3.22 & 2.67 & 1.75 \\
\hline
\end{tabular}

Table 2. Deviations $\delta$ between predicted and measured $\mathrm{P}_{\mathrm{Tx}}$ and $\mathrm{P}_{\mathrm{rec}}$, and corresponding standard deviations $\sigma$ for the UMTS femtocell case (also absolute deviations are provided).

again with indication of the LoS and NLoS points, based on a calibration factor $\mathrm{F}$ equal to $16 \mathrm{~dB}$ (see equation (6)). Table 2 lists the average deviation $\delta_{\text {avg }}$ between the predicted received power $\mathrm{P}_{\text {rec,femto }}^{\text {pred }}$ and the measured average received power $\mathrm{P}_{\text {rec, femto }}^{\text {avg }}$. Fig. 3 and Table 2 show that, again, very low prediction errors are obtained, especially in NLoS situations and indicate that the fixed calibration factor $\mathrm{F}$ suffices to accurately relate RSSI to received power predictions.

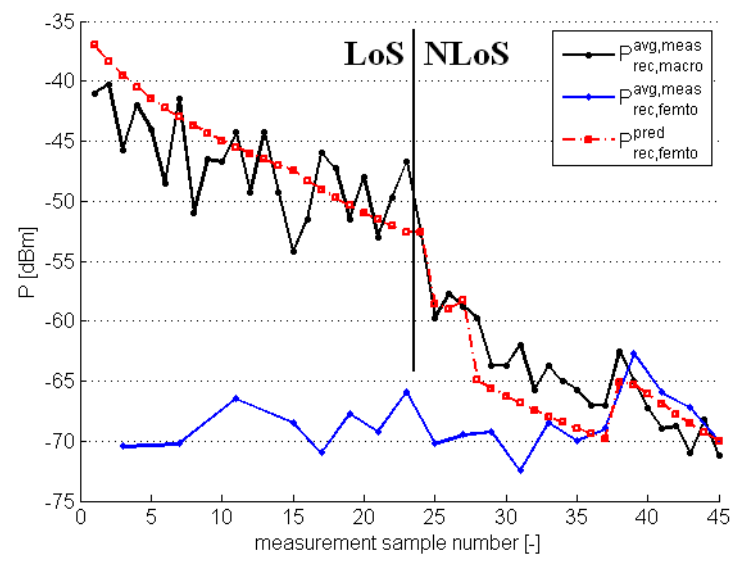

Figure 3. Measured received downlink power from macrocell base station ( $\left.\mathrm{P}_{\text {rec,macro }}^{\text {avg,meas }}\right)$ and measured $\left(\mathrm{P}_{\text {rec,femto }}^{\text {avg,meas }}\right)$ and predicted $\left(\mathrm{P}_{\text {rec,femto }}^{\text {pred }}\right)$ received power from FBS as a function of measurement sample number.

\section{RESULTS AND DISCUSSION}

Based on the models for UMTS femtocells and WiFi APs, electric-field and localized SAR distributions in the building of Fig. 1 will be presented. Also a comparison with different macrocell scenarios will be made.

\subsection{Network layout for the phone call scenarios}

\subsubsection{Connection with WiFi access points}

For the WiFi AP scenario, the WHIPP planning tool designs a network according to the WiFi coverage requirements defined in Section 2, based on link budget calculations (using the transmit and receive characteristics of Table 1). This yields a network with one WiFi AP $($ EIRP $=10 \mathrm{dBm}$, height $=200 \mathrm{~cm})$, at the location of the green dot in Fig. 1.

\subsubsection{Connection with UMTS femtocell}

For the UMTS femtocell scenario, the WHIPP planning tool also designs a network based on link budget calculations, using the UMTS transmit and receive characteristics of Table 1 . This yields a network in which one UMTS FBS $($ EIRP $=10 \mathrm{dBm}$, height $=200 \mathrm{~cm})$ is required to obtain the desired coverage. The optimal location of the FBS is the same as for the WiFi AP (green dot in Fig. 1).

\subsubsection{Connection with UMTS macrocell}

In this scenario, the mobile phone connects to an outdoor UMTS macrocell and electric-field and SAR values are determined from measurements inside the 
building. Figs. 2 and 3 show the received power and the transmitted power values at the blue locations of Fig. 1, as recorded by the mobile phone when connected to an outdoor UMTS macrocell. For this specific case, the figure shows that it is fair to assume that the electric-field strengths within the building are uniformly distributed, as well as the device's transmit powers (and SAR values). Based on the average recorded values, we assume a uniform received power value of $-69 \mathrm{dBm}$ and a uniform transmit power of $-16 \mathrm{dBm}$, at each location inside the building. This corresponds with an electricfield strength of $5.4 \mathrm{mV} / \mathrm{m}$ and a $\mathrm{SAR}_{10 \mathrm{~g}}$ value of $5.5 \mu \mathrm{W} / \mathrm{kg}$ (using equation (3))).

With respect to power control mechanisms, it was shown in [21] that for transmit powers up to $-10 \mathrm{dBm}$, a decrease of $1 \mathrm{~dB}$ in received power results in an equal increase of $1 \mathrm{~dB}$ in power transmitted by the mobile phone device. Further comparison of Figs. 2 and 3 confirms this assumption: the standard deviation of the sum of $\mathrm{P}_{\text {rec,macro }}^{\text {avg,meas }}$ and $\mathrm{P}_{\mathrm{Tx}}^{\text {avg,macro }}$ mas equals only $2.7 \mathrm{~dB}$. The femtocell scenario provides further confirmation: the standard deviation of the sum of $\mathrm{P}_{\text {rec,femto }}^{\text {avg,meas }}$ and $\mathrm{P}_{\text {Tx,femto }}^{\text {avg,meas }}$ is only $3.1 \mathrm{~dB}$. This constatation allows investigating different macrocell scenarios, where a higher received signal power (higher electric-field strength) will correspond to a lower transmitted power by the device (lower SAR value), due to power control. These different macrocell scenarios then each represent a building located closer or further from a UMTS MBS. Besides a uniform transmit power of $-16 \mathrm{dBm}$, also values of $-50,-40,-30,-20,-10,0$, and $10 \mathrm{dBm}$ will be simulated, together with the corresponding received power (electric-field) values. This total of eight different values represent eight different locations of the MBS relative to the building of Fig. 1. The transmitted and received powers, related by the UMTS power control mechanism, of these scenarios are listed in Table 3. Macro 1 represents a macrocell scenario where the base station is located relatively close to the considered building, while the scenarios with higher numbers represent situations where the path loss between the MBS and the building is progressively higher (e.g., due to higher distances and/or more obstacles between the MBS and the building).

\subsection{Downlink: electric-field strength}

Fig. 4 shows the electric-field strengths in the building for the UMTS and the WiFi scenario. The lower field strengths in the WiFi case are mainly due to the use of a duty cycle in WiFi communication. Fig. 5 compares the electric-field distributions of the different scenarios, and percentile values are listed in Table 4 for the UMTS femtocell and WiFi AP scenario. The femtocell percentile values are approximately a constant factor 7 higher than the WiFi percentile values. Table 3 shows the field strength percentile values for the

\begin{tabular}{|l|r|r|r|r|}
\hline scenario & $\begin{array}{r}\mathrm{P}_{\mathrm{Tx}} \\
{[\mathrm{dBm}]}\end{array}$ & $\begin{array}{r}\mathrm{SAR}_{10 \mathrm{~g}} \\
{[\mu \mathrm{W} / \mathrm{kg}]}\end{array}$ & $\begin{array}{r}\mathrm{P}_{\mathrm{Rx}} \\
{[\mathrm{dBm}]}\end{array}$ & $\begin{array}{r}\mathrm{E} \\
{[\mathrm{mV} / \mathrm{m}]}\end{array}$ \\
\hline Macro 1 & -50 & 0.021 & -35 & 270 \\
\hline Macro 2 & -40 & 0.21 & -45 & 85 \\
\hline Macro 3 & -30 & 2.1 & -55 & 27 \\
\hline Macro 4 & -20 & 21 & -65 & 8.5 \\
\hline Macro 5 & -16 & 52 & -69 & 5.4 \\
\hline Macro 6 & -10 & 210 & -75 & 2.7 \\
\hline Macro 7 & 0 & $2.1 \cdot 10^{3}$ & -85 & 0.85 \\
\hline Macro 8 & 10 & $2.1 \cdot 10^{4}$ & -95 & 0.27 \\
\hline
\end{tabular}

Table 3. Eight macrocell scenarios with respective device transmit power $\mathrm{P}_{T x}$, $S A R_{10 g}$ value, received power $\mathrm{P}_{\mathrm{Rx}}$, and received electric-field strength $\mathrm{E}$.

macrocell scenarios. There is for each scenario only one value for all percentiles, due to the assumption of a uniform distribution of the field values in the building. The eight macrocell scenarios were chosen to have a set of configurations with varying downlink exposure characteristics, from better than both WiFi and femtocell (Macro 8, worst connection with macrocell) to worse than both WiFi and femtocell (Macro 1, best connection with macrocell). Comparison of the percentiles for the WiFi/femto scenario (see Table 4) and the percentiles for the existing macrocell scenario (Macro 5, see Table 3), show that the Macro 5 scenario has E-field characteristics that lie in between those of the femtocell and WiFi scenario. Only Macro 7 and 8 (bad connection) have a lower DL exposure than the WiFi scenario. Due to the vicinity of the indoor base station, the femtocell scenario only has better DL exposure characteristics than Macro 1, 2, and 3.

\begin{tabular}{|r|r|r|r|}
\hline downlink DL & $\begin{array}{r}\mathbf{E}^{\mathbf{2 5}} \\
{[\mathbf{V} / \mathbf{m}]}\end{array}$ & $\begin{array}{r}\mathbf{E}^{\mathbf{5 0}} \\
{[\mathbf{V} / \mathbf{m}]}\end{array}$ & $\begin{array}{r}\mathbf{E}^{\mathbf{7 5}} \\
{[\mathbf{V} / \mathbf{m}]}\end{array}$ \\
\hline WiFi & $1.0 \cdot 10^{-3}$ & $1.6 \cdot 10^{-3}$ & $3.7 \cdot 10^{-3}$ \\
\hline Femto & $7.1 \cdot 10^{-3}$ & $1.1 \cdot 10^{-2}$ & $2.6 \cdot 10^{-2}$ \\
\hline uplink UL & $\mathbf{S A R}_{\mathbf{1 0 g}}^{\mathbf{2 5}}$ & $\mathbf{S A R}_{\mathbf{1 0 g}}^{\mathbf{5 0}}$ & $\begin{array}{r}\mathbf{S A R}_{10 g}^{\mathbf{7 5}} \\
{[\mathbf{W} / \mathbf{k g}]}\end{array}$ \\
& {$[\mathbf{W} / \mathbf{k g}]$} \\
\hline WiFi & \multicolumn{3}{|c|}{$9.8 \cdot 10^{-4}$} \\
\hline Femto & $6.8 \cdot 10^{-8}$ & $3.6 \cdot 10^{-7}$ & $9.2 \cdot 10^{-7}$ \\
\hline
\end{tabular}

Table 4. $25 \%$-, $50 \%$-, and $75 \%$-percentiles of electric-field strength $\mathbf{E}$ and localized $\mathrm{SAR}_{10 \mathrm{~g}}$ for UMTS femtocell and WiFi access point scenario.

\subsection{Uplink: localized $\mathrm{SAR}_{10 \mathrm{~g}}$}

Fig. 7 shows the $\mathrm{SAR}_{10 \mathrm{~g}}$ distribution in the building for the UMTS femtocell scenario. It is confirmed that 


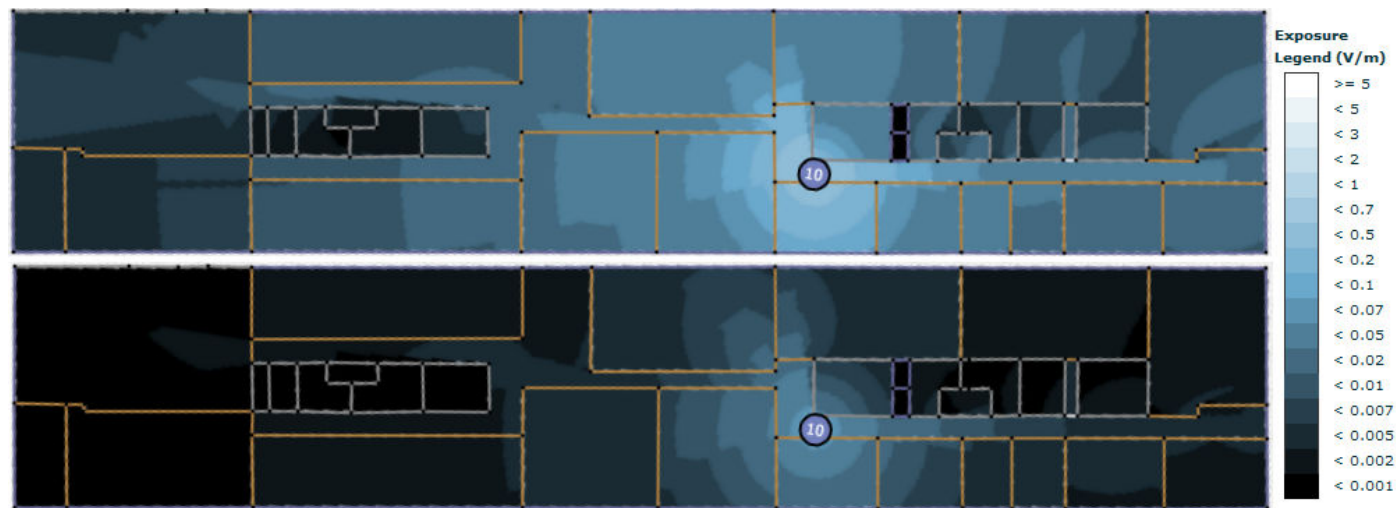

Figure 4. Electric-field strength in the considered building for UMTS femtocell scenario (top) and WiFi access point scenario (bottom).

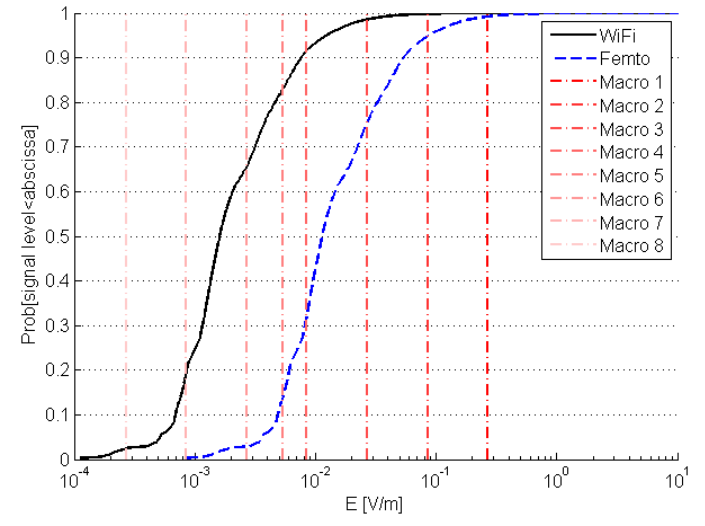

Figure 5. Electric-field strength distribution in the considered building for $\mathrm{WiFi}$ access point scenario, UMTS femtocell scenario, and eight UMTS macrocell scenarios.

due to power control, the locations closer to the FBS have lower transmit powers and thus lower $\mathrm{SAR}_{10 \mathrm{~g}}$ values. Table 4 shows that, due to the constant mobile phone uplink power of $20 \mathrm{dBm}$ in the WiFi scenario, the $25 \%-, 50 \%$-, and $75 \%$-percentile values are the same. Fig. 6 compares the $\mathrm{SAR}_{10 \mathrm{~g}}$ distributions of the different scenarios, and percentile values are listed in Table 4 for the UMTS femtocell and WiFi AP scenario. Fig. 6 and Table 4 show that due to the power control mechanism, the localized SAR values in the UMTS femtocell scenario are noticeably lower (i.e., 2722 times) than in the WiFi AP scenario. Table 3 shows the $\mathrm{SAR}_{10 \mathrm{~g}}$ percentile values for the macrocell scenarios. The femtocell scenario is better than all macrocell scenarios with respect to UL exposure. The WiFi scenario however causes a relatively high uplink exposure $(0.98 \mathrm{~mW} / \mathrm{kg})$, with values only exceeded by
Macro 7 and 8 (the two worst macrocell connection scenarios). The Macro 5 scenario causes $\mathrm{SAR}_{10 \mathrm{~g}}$ values 18.8 times lower than the WiFi scenario.

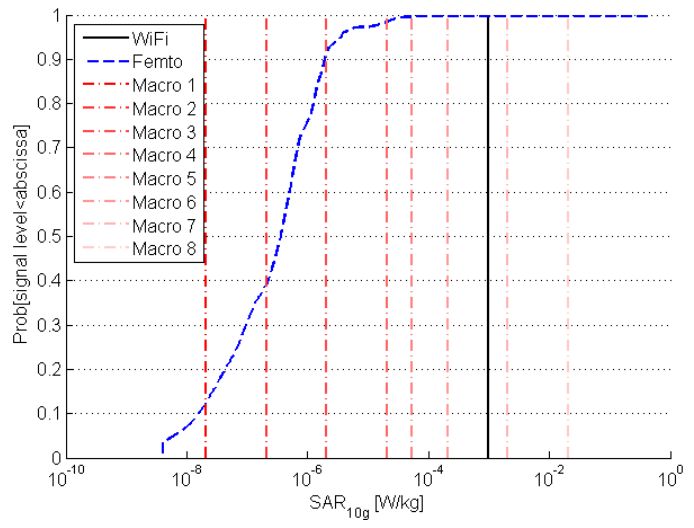

Figure 6. Localized $\mathrm{SAR}_{10 \mathrm{~g}}$ distribution in the considered building for WiFi access point scenario, UMTS femtocell scenario, and eight UMTS macrocell scenarios.

\subsection{Global scenario comparison}

Comparison of two random scenarios in Figs. 5 and 6 shows that in general, scenarios with lower downlink exposure (E) have higher uplink exposure. E.g., the WiFi scenario causes lower downlink electric-field strengths than the UMTS femtocell scenario, but the latter causes lower $\mathrm{SAR}_{10 \mathrm{~g}}$ values due to an efficient power control. Logically, in the macrocell scenarios closer to the MP (e.g., Macro 1), higher field strengths but lower $\mathrm{SAR}_{10 \mathrm{~g}}$ values are observed than in the macrocell scenarios further from the MP (e.g., Macro 8). However, to make 


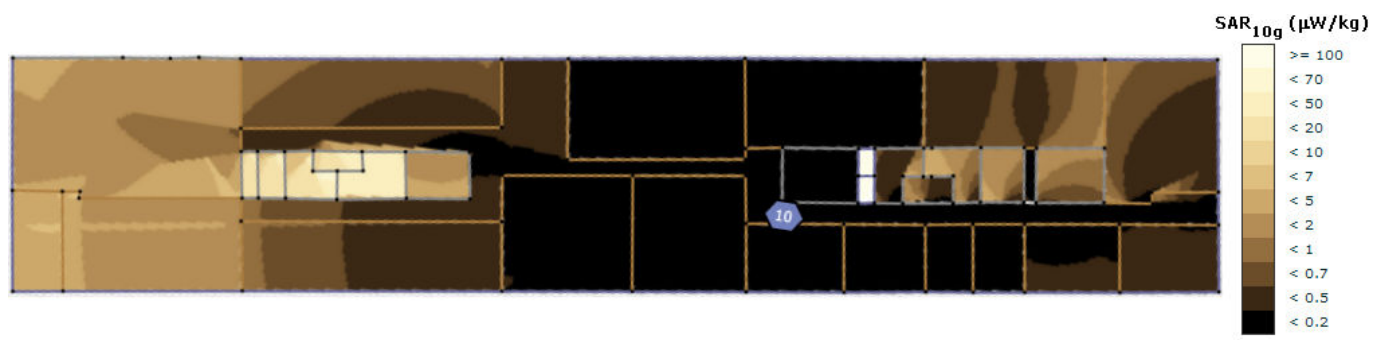

Figure 7. Localized $\mathrm{SAR}_{10 \mathrm{~g}}$ during a phone call at the different locations in the considered building for UMTS femtocell scenario, with indication of the femtocell base station (hexagon).

statements about the 'best' scenario, one has to calculate actual exposure doses [22,33]. Although it is hard to combine downlink and uplink exposure characteristics in a joint metric, conclusions will be drawn here, based on the calculation of localized and whole-body exposure doses for a single user in the network.

\subsubsection{Exposure doses for different scenarios}

In this section, 12 different scenarios will be investigated: the three connection scenarios (with UMTS MBS, UMTS FBS, or WiFi AP) for two average phone call connection times (high activity $(300 \mathrm{~s} / \mathrm{h})$ and low activity $(10 \mathrm{~s} / \mathrm{h})$ [33]) for two macrocell base station locations (MBS close to considered building (good connectivity) and MBS far from considered building (bad connectivity)). The call connection times are chosen in order to have a clear distinction between high and low activity. The times are expressed in $[\mathrm{s} / \mathrm{h}]$ instead of $[\mathrm{s} / \mathrm{day}]$, since this is more intuitive for an office environment where people reside during only a part of the day (e.g., 8 h). Scenarios Macro 2 (M2) and Macro 7 (M7) (see Table 3) will be used for the simulation of closer and further MBS locations respectively. The 12 scenarios will be compared based on the average localized exposure dose per hour $D_{\text {loc }}^{10 \mathrm{~g}}$ and the average whole-body exposure dose per hour $\mathrm{D}_{\mathrm{wb}}$, expressed in $\frac{\mathrm{J}}{\mathrm{kg} \cdot \mathbf{h}}$.

Exposure doses are calculated as the sum of different SAR contributions, which are calculated by multiplying the normalized SAR value (left column of Table 5) with the corresponding median transmitted or received powers (right column of Table 5). The normalized localized SAR values are obtained from Table 1, while the normalized whole-body SAR values are obtained from $[22,33]$, where it is assumed that $\mathrm{SAR}_{\mathrm{wb}, \mathrm{Tx}}^{\mathrm{WiFi}}$ is equal to $S A R_{w b, T x}^{\mathrm{UMTS}}$. The $\mathrm{SAR}_{\mathrm{wb}, \mathrm{Tx}}$ values are obtained for a cell phone placed to the right side of the head of the human model [22]. The $\mathrm{SAR}_{\mathrm{wb}, \mathrm{Tx}}$ values are calculated for the Duke model [38] for plane waves coming from the six major incident directions with two polarizations. It should again be noted that the whole-body SAR values will depend on the morphology of the user (child, adult) and the posture of the body (sitting, standing). The differences in whole-body SAR due to posture variations are less than for frontal-incident, single plane-wave exposure [36]. The whole-body SAR increases with decreasing size of the human body model. Vermeeren et al. showed that at $950 \mathrm{MHz}$ the whole-body SAR in a 5-year old spheroid child model is about $3 \mathrm{~dB}$ larger than in an adult male in a realistic (multi-path) exposure environment [37].

Table 6 lists the resulting 12 possible SAR contributions $[\mathrm{W} / \mathrm{kg}]$. For the localized exposure doses (C1-C4), it is assumed that only the device's transmit power contributes, during a time equal to the phone call connection time. For the whole-body exposure dose, it is assumed that the received power from the MBS contributes (C5-C6) during the entire considered time ( 1 hour), as well as the received power from the FBS (C7) or WiFi AP (C8) (if any), during the entire considered time (1 hour). Furthermore, also the contribution of the device's transmit power to the wholebody exposure (C9-C12) is accounted for, during the phone call connection time.

\begin{tabular}{|l|r|r||l|r|r|}
\hline \multicolumn{3}{|c||}{ Normalized SAR } & \multicolumn{3}{c|}{ Median Tx/Rx power } \\
\hline \hline SAR $_{\text {loc }}$ & Code & {$[\mathbf{W} / \mathbf{k g}]$} & $\mathbf{P}_{\mathrm{Tx}}$ & Code & {$[\mathbf{W}]$} \\
\hline $\mathrm{SAR}_{\text {loc10g, Tx }}^{\mathrm{UMTS}}$ & $\mathbf{A}$ & $0.415^{*}$ & $\mathrm{P}_{\mathrm{Tx}}^{\mathrm{M} 2}$ & $\mathbf{S}$ & $1.00 \cdot 10^{-7}$ \\
\hline $\mathrm{SAR}_{\text {loc10g,Tx }}^{\mathrm{WiFi}}$ & $\mathbf{B}$ & $0.049^{*}$ & $\mathrm{P}_{\mathrm{Tx}}^{\mathrm{M7}}$ & $\mathbf{T}$ & $1.00 \cdot 10^{-3}$ \\
\hline $\mathbf{S A R}_{\mathrm{wb}}^{\mathrm{fx}}$ & & & $\mathrm{P}_{\mathrm{Tx}}^{\mathrm{femto}}$ & $\mathbf{U}$ & $1.73 \cdot 10^{-7}$ \\
\hline $\mathrm{SAR}_{\mathrm{wb}, \mathrm{Tx}}^{\mathrm{UMTS}}$ & $\mathbf{C}$ & $0.00495^{*}$ & $\mathrm{P}_{\mathrm{Tx}}^{\mathrm{WiFi}}$ & $\mathbf{V}$ & $2.00 \cdot 10^{-3}$ \\
\hline $\mathrm{SAR}_{\mathrm{wb}, \mathrm{Tx}}^{\mathrm{WiFi}}$ & $\mathbf{D}$ & $0.00495^{*}$ & $\mathbf{P}_{\mathbf{R x}}$ & & {$\left[\mathbf{W} / \mathbf{m}^{\mathbf{2}}\right]$} \\
\hline & & & $\mathrm{P}_{\mathrm{Rx}}^{\mathrm{M2}}$ & $\mathbf{W}$ & $3.16 \cdot 10^{-8}$ \\
\hline $\mathrm{SAR}_{\mathrm{wb}, \mathrm{Rx}}^{\mathrm{UMTS}}$ & $\mathbf{E}$ & $0.003^{*} *$ & $\mathrm{P}_{\mathrm{Rx}}^{\mathrm{M7}}$ & $\mathbf{X}$ & $3.16 \cdot 10^{-12}$ \\
\hline $\mathrm{SAR}_{\mathrm{wb}, \mathrm{Rx}}^{\mathrm{WiF}}$ & $\mathbf{F}$ & $0.0028^{* *}$ & $\mathrm{P}_{\mathrm{Rx}}^{\mathrm{femto}}$ & $\mathbf{Y}$ & $5.01 \cdot 10^{-10}$ \\
\hline & & & $\mathrm{P}_{\mathrm{Rx}}^{\mathrm{WiFi}}$ & $\mathbf{Z}$ & $7.94 \cdot 10^{-12}$ \\
\hline
\end{tabular}

Table 5. Values for normalised SAR $*^{*}=$ per $1 \mathrm{~W}$ transmitted power; $* *=$ per $1 \mathrm{~W} / \mathrm{m}^{2}$ received power) and median transmitted power to and received power from the different considered base stations. 
D. PLETS ET AL

\begin{tabular}{|c|c|c|c|c|}
\hline & $\begin{array}{l}\text { SAR } \\
\text { contributions }\end{array}$ & $\begin{array}{l}\text { calculated } \\
\text { as* }\end{array}$ & $\begin{array}{l}\text { SAR value } \\
{[\mathrm{W} / \mathrm{kg}]}\end{array}$ & Code \\
\hline \multirow{4}{*}{$\begin{array}{c}\text { Tx } \\
\text { (UL) } \\
- \\
\text { loc }\end{array}$} & $\mathrm{SAR}_{\mathrm{loc10g}, \mathrm{Tx}}^{\mathrm{M} 2}$ & $A \cdot S$ & $4.15 \cdot 10^{-8}$ & $\mathrm{C1}$ \\
\hline & $\mathrm{SAR}_{\mathrm{loc} 10 \mathrm{~g}, \mathrm{Tx}}^{\mathrm{M7}}$ & $\mathrm{A} \cdot \mathrm{T}$ & $4.15 \cdot 10^{-4}$ & $\mathrm{C2}$ \\
\hline & SAR $_{\text {loc10g, Tx }}^{\text {femto }}$ & $A \cdot U$ & $7.18 \cdot 10^{-8}$ & $\mathrm{C3}$ \\
\hline & $\mathrm{SAR}_{\mathrm{loc10g}, \mathrm{Tx}}^{\mathrm{WiFi}}$ & $\mathrm{B} \cdot \mathrm{V}$ & $9.80 \cdot 10^{-5}$ & $\mathrm{C4}$ \\
\hline \multirow{4}{*}{$\begin{array}{c}\mathrm{Rx} \\
(\mathrm{DL}) \\
- \\
\mathrm{wb}\end{array}$} & $\mathrm{SAR}_{\mathrm{wb}, \mathrm{Rx}}^{\mathrm{M2}}$ & $E \cdot W$ & $9.48 \cdot 10^{-11}$ & C5 \\
\hline & $\mathbf{S A R}_{\mathrm{wb}, \mathbf{R x}_{\mathrm{x}}}^{\mathrm{M7}}$ & $E \cdot X$ & $9.48 \cdot 10^{-15}$ & C6 \\
\hline & $\mathbf{S A R}_{\mathrm{wb}, \mathbf{R x}}^{\text {femto }}$ & $\mathrm{E} \cdot \mathrm{Y}$ & $1.50 \cdot 10^{-12}$ & C7 \\
\hline & $\mathrm{SAR}_{\mathrm{wb}, \mathbf{R x}_{\mathrm{x}}}^{\mathrm{WiFi}}$ & $\mathrm{F} \cdot \mathrm{Z}$ & $2.22 \cdot 10^{-14}$ & C8 \\
\hline \multirow{4}{*}{$\begin{array}{c}\text { Tx } \\
\text { (UL) } \\
- \\
\text { wb }\end{array}$} & $\mathrm{SAR}_{\mathrm{wb}, \mathrm{Tx}}^{\mathrm{M} 2}$ & $\mathrm{C} \cdot \mathrm{S}$ & $4.95 \cdot 10^{-10}$ & C9 \\
\hline & $\mathrm{SAR}_{\mathrm{wb}, \mathrm{Tx}}^{\mathrm{M7}}$ & $\mathrm{C} \cdot \mathrm{T}$ & $4.95 \cdot 10^{-6}$ & C10 \\
\hline & SAR $_{\mathrm{wb}, \mathrm{Tx}}^{\text {femto }}$ & $\mathrm{C} \cdot \mathrm{U}$ & $8.56 \cdot 10^{-10}$ & C11 \\
\hline & $\mathbf{S A R}_{\mathrm{wb}, \mathrm{Tx}}^{\mathrm{WiF}}$ & $\mathrm{D} \cdot \mathrm{V}$ & $9.90 \cdot 10^{-6}$ & $\mathrm{C12}$ \\
\hline
\end{tabular}

Table 6. Values for localized and whole-body SAR due to the transmitted and received powers in the different scenarios $(*=$ see Table 5 ).

Table 7 shows the calculated exposure doses, based on the multiplication of the SAR contributions from Table 6 with the duration of the exposure contribution. The scenarios with the lowest dose $\left(D_{\mathrm{loc}}^{10 \mathrm{~g}}, \mathrm{D}_{\mathrm{wb}}\right)$ are indicated in bold in Table 7. In case locations in the building have a good connection with the MBS (M2), it is better to rely on the macrocell: Table 7 shows that the macrocell scenario (1 and 4) produces the lowest localized $\left(\mathrm{D}_{\mathrm{loc}}^{10 \mathrm{~g}}\right)$ and whole-body $\left(\mathrm{D}_{\mathrm{wb}}\right)$ exposure doses, both for long total connection times (HI, scenarios 12-3) and short total connection times (LO, scenarios 4-5-6). This is due to the fact that the uplink exposure is very limited due to good connection with the macrocell, and in the femtocell and WiFi scenario, the macrocell downlink exposure is present anyway.

When the MP has a bad connection with the MBS (M7), the femtocell solution is by far the best configuration, again both for long (HI, scenarios 7-89) and short (LO, scenarios 10-11-12) connection times. Reductions of a factor more than 5000 are obtained for localized (5814) and whole-body (5687) exposure doses for long phone call connections (scenario 8 vs. scenario 7 in Table 7). This was expected due to the advantages of the UMTS power control mechanism. One could expect nonetheless that the relatively high (compared to the Macro 7 and WiFi scenarios, see also Fig. 5) and continuous exposure to the FBS's radiation would make the femtocell configuration less beneficial for short phone call connection times (LO, scenarios 10-11-12). However, the high whole-body exposure dose due to the MP's transmitted power when even a short phone call is made, causes the total whole-body exposure dose to be higher for the WiFi and macrocell scenario. The use of a femtocell reduces the localized exposure dose by a factor 5780 and the whole-body exposure dose by a factor 3536 compared to a macrocell (scenario 11 vs. scenario 10 in Table 7). This is due to the high value of $\mathrm{SAR}_{\mathrm{wb}, \mathrm{Tx}}^{\mathrm{M} 7}(\mathrm{C} 10)$ and $\mathrm{SAR}_{\mathrm{wb}, \mathrm{Tx}}^{\mathrm{WiFi}}$ (C12) compared to $\mathrm{SAR}_{\mathrm{wb}, \mathrm{Tx}}^{\text {femto }}(\mathrm{C} 11)$ (see Table 6). It can be concluded that it is advantageous to install a femtocell in the building, when the connection with the macrocell base station is bad. Not only is this conclusion valid in terms of exposure, it will also be beneficial to install a femtocell in terms of Quality of Service: the femtocell base station will provide a better connection than the macrocell base station and will allow higher data rates. When the macrocell connection is good, the macrocell solution is slightly better in terms of exposure (scenario 1 vs. scenario 2 and scenario 4 vs. scenario 5 in Table 7) and is at the same time better in terms of Quality of Service (higher median received power (W vs. Y) and lower median transmitted power (S vs. U), see Table 5). The WiFi solution is never preferred in terms of exposure, but on the other hand, it allows higher-rate data traffic compared to UMTS.

\section{CONCLUSIONS AND FUTURE WORK}

In this paper, the first heuristic network calculator for both whole-body exposure originating from base stations or access points (downlink exposure) and localized exposure from the mobile device (uplink exposure) in indoor wireless networks is presented. The accuracy of the proposed prediction models is better than $3 \mathrm{~dB}$. Three phone call scenarios are investigated (UMTS macrocell, UMTS femtocell, and WiFi voiceover-IP) and they are compared with respect to the level of electric-field strength and localized $\mathrm{SAR}_{10 \mathrm{~g}}$ distributions. Calculation of exposure doses for the different scenarios indicate that it is beneficial to install a femtocell base station, in particular when the existing macrocell connection is bad (exposure dose reductions by up to a factor 5000).

\section{ACKNOWLEDGEMENT}

This work has been carried out with the financial support of the iMinds-RAILS project and the FP7Lexnet project. W. Joseph is a Post-Doctoral Fellow of the FWO-V (Research Foundation-Flanders).

\section{REFERENCES}

1. IEEE Std C95.1, IEEE Standard for Safety Levels with Respect to Human Exposure to Radio Frequency Electromagnetic Fields, $3 \mathrm{kHz}$ to 300 GHz. (1999).

2. ICNIRP, Guidelines for limiting exposure to timevarying electric, magnetic, and electromagnetic fields (up to $300 \mathrm{GHz}$ ). Health Physics 74(4):494522 (April 1998). 
PREDICTION AND COMPARISON OF INDOOR E AND SAR

\begin{tabular}{|c|c|c|c|c|}
\hline \multicolumn{5}{|c|}{ Good connection with macrocell base station (M2) } \\
\hline Scenario & calculation $\mathrm{D}_{\mathrm{loc}}^{10 \mathrm{~g}} *$ & $\begin{array}{c}\mathbf{D}_{\mathrm{loc}}^{10 \mathrm{~g}} \\
{\left[\frac{\mathrm{J}}{\mathrm{kg} \cdot \mathrm{h}}\right]}\end{array}$ & calculation $\mathrm{D}_{\mathrm{wb}} *$ & $\begin{array}{r}\mathbf{D}_{\mathbf{w b}} \\
{\left[\frac{\mathrm{J}}{\mathrm{kg} \cdot \mathrm{h}}\right]}\end{array}$ \\
\hline 1.Macro-HI & $300 \mathrm{~s} / \mathrm{h} \cdot \mathrm{C} 1$ & $1.25 \cdot 10^{-5}$ & $3600 \mathrm{~s} / \mathrm{h} \cdot \mathrm{C} 5+300 \mathrm{~s} / \mathrm{h} \cdot \mathrm{C} 9$ & $4.90 \cdot 10^{-7}$ \\
\hline 2.Femto-HI & $300 \mathrm{~s} / \mathrm{h} \cdot \mathrm{C} 3$ & $2.15 \cdot 10^{-5}$ & $3600 \mathrm{~s} / \mathrm{h} \cdot \mathrm{C} 5+3600 \mathrm{~s} / \mathrm{h} \cdot \mathrm{C} 7+300 \mathrm{~s} / \mathrm{h} \cdot \mathrm{C} 11$ & $6.04 \cdot 10^{-7}$ \\
\hline 3.WiFi-HI & $300 \mathrm{~s} / \mathrm{h} \cdot \mathrm{C} 4$ & $2.94 \cdot 10^{-2}$ & $3600 \mathrm{~s} / \mathrm{h} \cdot \mathrm{C} 5+3600 \mathrm{~s} / \mathrm{h} \cdot \mathrm{C} 8+300 \mathrm{~s} / \mathrm{h} \cdot \mathrm{C} 12$ & $2.94 \cdot 10^{-3}$ \\
\hline 4.Macro-LO & $10 \mathrm{~s} / \mathrm{h} \cdot \mathrm{C} 1$ & $4.15 \cdot 10^{-7}$ & $3600 \mathrm{~s} / \mathrm{h} \cdot \mathrm{C} 5+10 \mathrm{~s} / \mathrm{h} \cdot \mathrm{C} 9$ & $3.46 \cdot 10^{-7}$ \\
\hline 5.Femto-LO & $10 \mathrm{~s} / \mathrm{h} \cdot \mathrm{C} 3$ & $7.18 \cdot 10^{-7}$ & $3600 \mathrm{~s} / \mathrm{h} \cdot \mathrm{C} 5+3600 \mathrm{~s} / \mathrm{h} \cdot \mathrm{C} 7+10 \mathrm{~s} / \mathrm{h} \cdot \mathrm{C} 11$ & $3.55 \cdot 10^{-7}$ \\
\hline 6.WiFi-LO & $10 \mathrm{~s} / \mathrm{h} \cdot \mathrm{C} 4$ & $9.80 \cdot 10^{-4}$ & $3600 \mathrm{~s} / \mathrm{h} \cdot \mathrm{C} 5+3600 \mathrm{~s} / \mathrm{h} \cdot \mathrm{C} 8+10 \mathrm{~s} / \mathrm{h} \cdot \mathrm{C} 12$ & $9.93 \cdot 10^{-5}$ \\
\hline \multicolumn{5}{|c|}{ Bad connection with macrocell base station (M7) } \\
\hline & calculation $\mathrm{D}_{\operatorname{loc}}^{10 \mathrm{~g}} *$ & $\begin{array}{c}D_{\text {loc }}^{10 g} \\
{\left[\frac{\mathrm{J}}{\mathrm{kg} \cdot \mathrm{h}}\right]}\end{array}$ & calculation $\mathrm{D}_{\mathrm{wb}} *$ & $\begin{array}{r}\mathbf{D}_{\mathbf{w b}} \\
{\left[\frac{\mathrm{J}}{\mathrm{kg} \cdot \mathrm{h}}\right]}\end{array}$ \\
\hline 7.Macro-HI & $300 \mathrm{~s} / \mathrm{h} \cdot \mathrm{C} 2$ & $1.25 \cdot 10^{-1}$ & $3600 \mathrm{~s} / \mathrm{h} \cdot \mathrm{C} 6+300 \mathrm{~s} / \mathrm{h} \cdot \mathrm{C} 10$ & $1.49 \cdot 10^{-3}$ \\
\hline 8.Femto-HI & $300 \mathrm{~s} / \mathrm{h} \cdot \mathrm{C} 3$ & $2.15 \cdot 10^{-5}$ & $3600 \mathrm{~s} / \mathrm{h} \cdot \mathrm{C} 6+3600 \mathrm{~s} / \mathrm{h} \cdot \mathrm{C} 7+300 \mathrm{~s} / \mathrm{h} \cdot \mathrm{C} 11$ & $2.62 \cdot 10^{-7}$ \\
\hline 9.WiFi-HI & $300 \mathrm{~s} / \mathrm{h} \cdot \mathrm{C} 4$ & $2.94 \cdot 10^{-2}$ & $3600 \mathrm{~s} / \mathrm{h} \cdot \mathrm{C} 6+3600 \mathrm{~s} / \mathrm{h} \cdot \mathrm{C} 8+300 \mathrm{~s} / \mathrm{h} \cdot \mathrm{C} 12$ & $2.97 \cdot 10^{-3}$ \\
\hline 10.Macro-LO & $10 \mathrm{~s} / \mathrm{h} \cdot \mathrm{C} 2$ & $4.15 \cdot 10^{-3}$ & $3600 \mathrm{~s} / \mathrm{h} \cdot \mathrm{C} 6+10 \mathrm{~s} / \mathrm{h} \cdot \mathrm{C} 10$ & $4.95 \cdot 10^{-5}$ \\
\hline 11.Femto-LO & $10 \mathrm{~s} / \mathrm{h} \cdot \mathrm{C} 3$ & $7.18 \cdot 10^{-7}$ & $3600 \mathrm{~s} / \mathrm{h} \cdot \mathrm{C} 6+3600 \mathrm{~s} / \mathrm{h} \cdot \mathrm{C} 7+10 \mathrm{~s} / \mathrm{h} \cdot \mathrm{C} 11$ & $1.40 \cdot 10^{-8}$ \\
\hline 12.WiFi-LO & $10 \mathrm{~s} / \mathrm{h} \cdot \mathrm{C} 4$ & $9.80 \cdot 10^{-4}$ & $3600 \mathrm{~s} / \mathrm{h} \cdot \mathrm{C} 6+3600 \mathrm{~s} / \mathrm{h} \cdot \mathrm{C} 8+10 \mathrm{~s} / \mathrm{h} \cdot \mathrm{C} 12$ & $9.90 \cdot 10^{-5}$ \\
\hline
\end{tabular}

Table 7. Localized and whole-body exposure doses $\mathrm{D}$ for the different scenarios $(\mathrm{HI}=$ high phone call activity, LO $=$ low phone call activity; * = see Table 6 ; bold = lowest dose for high/low phone call activity).

3. K. R. Foster, Radiofrequency exposure from wireless LANs using Wi-Fi technology. Health Physics 92:280-289 (2007).

4. W. Joseph and P. Frei and M. Roösli and G. Thuróczy and P. Gajsek and T. Trcek and J. Bolte and G. Vermeeren and E. Mohler and P. Juhsz and V. Finta and L. Martens, Comparison of personal radio frequency electromagnetic field exposure in different urban areas across Europe. Environmental Research 110(7):658-663 (2010).

5. W. Joseph and P. Frei and M. Roösli and G. Vermeeren and J. Bolte and G. Thuróczy and P. Gajsek and T. Trcek and E. Mohler and P. Juhasz and V. Finta and L. Martens, Between-country comparison of whole-body SAR from personal exposure data in urban areas. Bioelectromagnetics 33(8):682-694 (December 2012).

6. P. Frei and E. Mohler and A. Bürgi and J. Fröhlich and G. Neubauer and C. Braun-Fahrländer and M. Roosli, A prediction model for personal radio frequency electromagnetic field exposure. Science of The Total Environment 408(1):102-108 (2009).

7. A. Boursianis and P. Vanias and T. Samaras, Measurements for assessing the exposure from 3G femtocells. Radiation Protection Dosimetry 150(2):158-167 (2012).
8. W. Joseph and L. Verloock and F. Goeminne and G. Vermeeren and L. Martens, Assessment of RF exposures from emerging wireless communication technologies in different environments. Health Physics 102(2):161-172 (February 2012).

9. Zhong Ji and Bin-Hong Li and Hao-Xing Wang and Hsing-Yi Chen and T.K. Sarkar, Efficient ray-tracing methods for propagation prediction for indoor wireless communications. IEEE Antennas and Propagation Magazine 43(2):41-49 (April 2001).

10. R.P. Torres and L. Valle and M. Domingo and M.C. Diez, CINDOOR: an engineering tool for planning and design of wireless systems in enclosed spaces. IEEE Antennas and Propagation Magazine 41(4):11-22 (September 1999).

11. G. Wölfle and R. Wahl and P. Wertz and P. Wildbolz and F. Landstorfer, Dominant Path Prediction Model for Indoor Scenarios. German Microwave Conference (GeMIC) Ulm, Germany (April 2005).

12. A.G. Dimitriou and S. Siachalou and A. Bletsas and J.N. Sahalos, An Efficient Propagation Model for Automatic Planning of Indoor Wireless Networks. 3rd European Conference on Antennas and Propagation Barcelona, Spain (April 2010).

13. P. Sebastiao, R. Tome, F. Velez, A. Grilo, F. Cercas, D. Robalo, A. Rodrigues, F. F. Varela and 


\section{PLETS ET AL}

C. X. P. Nunes, WLAN Planning Tool: a TechnoEconomic Perspective. COST 2100 TD(09)935 meeting Vienna, Austria (September 2009).

14. P. Russo and G. Cerri and V. Vespasiani, A Numerical Coefficient for Evaluation of the Environmental Impact of Electromagnetic Fields Radiated by Base Stations for Mobile Communications. Bioelectromagnetics 31:613-621 (2010).

15. G. Koutitas, Green Network Planning of Single Frequency Networks. IEEE Transactions on Broadcasting 56(4):541-550 (December 2010).

16. W. Joseph and D. Pareit and G. Vermeeren and D. Naudts and L. Verloock and L. Martens and I. Moerman, Determination of the duty cycle of WLAN for realistic radio frequency electromagntic field exposure assessment. Progress in Biophysics \& Molecular Biology 111(1):30-36 (January 2013).

17. S. Phaiboon, An empirically based path loss model for indoor wireless channels in laboratory building. TENCON '02. Proceedings. 2002 IEEE Region 10 Conference on Computers, Communications, Control and Power Engineering 2:1020-1023 (October 2002).

18. J.M. Keenan and A.J. Motley, Radio Coverage in Buildings. BTSJ 8(1):19-24 (January 1990).

19. D. Plets and W. Joseph and K. Vanhecke and E. Tanghe and L. Martens, Coverage Prediction and Optimization Algorithms for Indoor Environments. EURASIP Journal on Wireless Communications and Networking, Special Issue on Radio Propagation, Channel Modeling, and Wireless, Channel Simulation Tools for Heterogeneous Networking Evaluation url = http://jwcn.eurasipjournals.com/ content/2012/ 1/123, 1 (2012).

20. D. Plets, W. Joseph, K. Vanhecke, and L. Martens, Exposure Optimization in Indoor Wireless Networks by Heuristic Network Planning. Progress In Electromagnetic Research (PIER) 139:445-478 (2013).

21. Gati, A. and Conil, E. and Man-Fai Wong and Wiart, J., Duality Between Uplink Local and Downlink Whole-Body Exposures in Operating Networks. Electromagnetic Compatibility, IEEE Transactions on 52(4):829-836 (2010).

22. Lauer O., Frei P. Gosselin MC., Joseph W., Roosli M. and Frohlich J., Combining near-and far-field exposure for an organ-specific and whole-body RF-EMF proxy for epidemiological research: a reference case. Bioelectromagnetics 34(5):366-374 (2013)
23. SAR Database. url="http://www.sardatabase.com", note ="Last accessed on March 15, 2013".

24. Skype. How much bandwidth does Skype need? url="https://support.skype.com/en/faq/FA1417/howmuch-bandwidth-does-skype-need ", note ="Last accessed on July 15, 2013".

25. TiWi-SL MODULE Datasheet.url= "http://www.lsr.com/downloads/products/330-0085.pdf ", note ="Last accessed on July 18, 2013".

26. Federal Communications Commission. Office of Engineering and Technology. url = https://apps.fcc.gov/ oetcf/eas/reports/ViewExhibitReport.cfm?mode= Exhibits\&calledFromFrame=N\&application_id $=922267$, note ="Last accessed on May 27, 2013".

27. Federal Communications Commission. Office of Engineering and Technology. url = https://apps.fcc.gov/ oetcf/eas/reports/ViewExhibitReport.cfm?mode= Exhibits\&calledFromFrame=N\&application $\_$id $=456890$, note ="Last accessed on May 27, 2013".

28. CENELEC European Committee for Electrotechnical Standardisation TC 106x WG1 EN 50492 in situ. Basic standard for the in-situ measurement of electromagnetic field strength related to human exposure in the vicinity of base stations; 2008.

29. Federal Communications Commission (FCC). Evaluating Compliance with FCC Guidelines for Human Exposure to Radiofrequency Electromagnetic Fields. Washington, DC, Tech. Rep. Suppl. C to OET Bulletin 65; 2001.

30. Institute of Electrical and Electronics Engineers IEEE C95.1-2005. IEEE Standard for Safety Levels with Respect to Human Exposure to Radio Frequency Electromagnetic Fields, $3 \mathrm{kHz}$ to 300 GHz. Piscataway New York: IEEE; 2005.

31. International Electrotechnical Commission (IEC), Determination of RF field strength and SAR in the vicinity of radiocommunication base stations for the purpose of evaluating human exposure. IEC, 2011.

32. International Commission on Non-ionizing Radiation Protection (ICNIRP), Guidelines for limiting exposure to time-varying electric, magnetic, and electromagnetic fields up to $300 \mathrm{GHz}$. Health Physics IEC, 74(4):494-522 (1998).

33. S. Aerts, D. Plets, L. Verloock, L. Martens, and W. Joseph, Assessment and Comparison of RF EMF Exposure in Femtocell and Macrocell Scenarios. Radiation Protection Dosimetry, accepted

34. A. Peyman, C. Gabriel, E. H. Grant, G. Vermeeren, and L. Martens, Variation of the dielectric properties of tissues with age: the effect on the values of SAR in children when exposed 
to walkietalkie devices. Physics in Medicine and Biology 54(2):227-241 (2009).

35. A. Christ, M.-C. Gosselin, M. Christopoulou, S. Kühn, and N. Kuster, Age-dependent tissuespecific exposure of cell phone users. Physics in Medicine and Biology 55(7):1767-1783 (2010).

36. T. Uusitupa, I. Laakso, S. Ilvonen, and K. Nikoskinen, SAR variation study from 300 to $5000 \mathrm{MHz}$ for 15 voxel models including different postures. Phys. Med. Biol 55:1157-76 (2010).

37. G. Vermeeren, W. Joseph, and L. Martens, Wholebody SAR in spheroidal adult and child phantoms in realistic exposure environment. ELECTRONICS LETTERS 44(13):790-791 (2008).

38. A. Christ, W. Kainz, E. G. Hahn, K. Honegger, M. Zefferer, E. Neufeld, W. Rascher, R. Janka, W. Bautz, J. Chen, B. Kiefer, P. Schmitt, H.-P. Hollenbach, J. Shen, M. Oberle, D. Szczerba, A. Kam, J. W. Guag, and N. Kuster, The Virtual Familydevelopment of surface-based anatomical models of two adults and two children for dosimetric simulations. Physics in Medicine and Biology 55(2):N23-N38 (2010). 